The following paper was presented at The 9th Workshop on Disfluency in Spontaneous Speech (DiSS 2019) held at ELTE Eötvös Loránd University in Budapest, Hungary on 12-13 September, 2019.

Title: Disfluencies in mildly intellectually disabled young adults' spontaneous speech

Author(s): Julianna Jankovics and Luca Garai

Abstract: $\quad$ The study analyzes various hesitations and repairs in the spontaneous speech of mildly intellectually disabled women. The main research questions of the study focus on the similarities and differences in the frequency of disfluencies and the duration of pauses between the spontaneous speech of mildly intellectually disabled and mentally healthy young adults. Our results show that hesitation phenomena were more frequent among intellectually disabled subjects in spontaneous speech, while repairs occurred more frequently among control subjects in guided spontaneous speech.

DOI: $\quad$ https://doi.org/10.21862/diss-09-021-jank-gara

Citation (JIPA): Jankovics, Julianna and Luca Garai. 2019. Disfluencies in mildly intellectually disabled young adults' spontaneous speech. In: R. L. Rose \& R. Eklund (eds.), Proceedings of DiSS 2019, The 9th Workshop on Disfluency in Spontaneous Speech, 12-13 September, 2019, Budapest, Hungary, 79-82.

The complete proceedings for DiSS 2019 are available as follows.

ISBN: $\quad$ 978-963-489-063-8

DOI: $\quad$ https://doi.org/10.21862/diss-09

DiSS 2019 was sponsored by The Faculty of Humanities, ELTE Eötvös Loránd University and the International Speech Communication Association (ISCA).
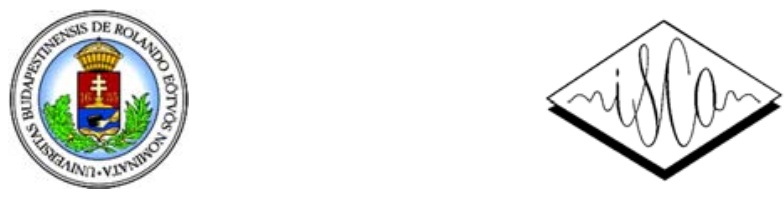


\title{
Disfluencies in mildly intellectually disabled young adults' spontaneous speech
}

\author{
Julianna Jankovics ${ }^{1}$ and Luca Garai ${ }^{2}$ \\ ${ }^{1}$ Doctoral School of Linguistics, Applied Linguistics, Eötvös Loránd University, Budapest, Hungary \\ ${ }^{2}$ Department of English Linguistics, Eötvös Loránd University, Budapest, Hungary
}

\begin{abstract}
The study analyzes various hesitations and repairs in the spontaneous speech of mildly intellectually disabled women. The main research questions of the study focus on the similarities and differences in the frequency of disfluencies and the duration of pauses between the spontaneous speech of mildly intellectually disabled and mentally healthy young adults. Our results show that hesitation phenomena were more frequent among intellectually disabled subjects in spontaneous speech, while repairs occurred more frequently among control subjects in guided spontaneous speech.
\end{abstract}

\section{Introduction}

The definition of disfluency is not consistent (Lickley, 2015), as the phenomena occurring in spontaneous speech are investigated by many fields of science (Roberts, Meltzer \& Wilding, 2009). According to Lickley (2015: 451-452), who also notes that there is no universal definition for the term, disfluency occurs when a speaker fails to convey their message without any error, correction, or struggle to express themselves, but he also states that perfect fluency is almost impossible for most speakers and that "everyone is disfluent some of the time."

The classification of disfluency types is also not consistent in the literature. Those analyzing typical speech usually divide these phenomena in two groups, hesitations and repair-type disfluencies. While the former occur when the speaker is unsure of what they want to say yet and uses these disfluencies as devices to stall for time, the latter are present when the speaker's message is not realized correctly or when the rules of the language are breached (cf. Lickley, 2015). Clinical literature differentiates between typical speech and fluency disorders based on the frequency and types of disfluencies. The latter classification mainly encompasses the analysis of cluttering and stuttering (cf. Bóna, 2018). These works make a distinction between typical and stuttering-like disfluencies.

Numerous studies have focused on these phenomena occurring in the speech of people with mental disabilities. Rossi et al. (2011) investigated the speech of subjects with Williams Syndrome and found that disfluencies, particularly hesitations, repetitions, and pauses, were significantly more frequent in their speech than in that of their control subjects. Coppens-Hofman et al. (2013) studied the spontaneous speech of adults with mild or moderate intellectual disabilities and their results found typical dysfluency patterns which feature cluttering much more prominently when compared to stuttering.

The current research focuses on disfluencies in the speech of mildly intellectually disabled subjects (with an IQ score between 50 and 69 points, ICD-11, 2018) and compares them to those in the speech of mentally healthy subjects. The study follows the classification outlined by Lickley (2015), which differentiates between two disfluency types, hesitations (including prolongation, silent and filled pauses, and repetition) and repairs (including substitution, insertion, and deletion). All phenomena are included in the current analysis, except for prolongation.

The study aims to discover how frequently the various disfluency types occur in two kinds of spontaneous speech and what differences there are between the disfluencies of female subjects with and without mental disabilities. Based on the literature, the following hypotheses were outlined:

(1) mildly intellectually disabled subjects exhibit more hesitations in both speech types when compared to control subjects;

(2) the spontaneous speech of intellectually disabled people contains more disfluencies in total;

(3) filled and silent pauses in the speech of intellectually disabled subjects are longer in duration.

\section{Subjects, material, and method}

The subjects of the current research were 10 mildly intellectually disabled women between the ages of 17.8 and 21.7 years (ID1-ID10) and 10 mentally healthy women (control subjects) of similar ages, between 18.1 and 29.1 years (C1-C10). All participants were native speakers of Hungarian, spoke the standard vernacular, and were nonsmokers. The speech samples were all recorded in a quiet environment. In total, four types of speech were recorded, of which two are subject to analysis in the current paper. In the Interview, the subjects were asked about school or work, free time activities, and 
family by the recording operator. During the Picture Story, subjects had to tell a story using a coherent set of eight black-and-white images. In both exercises, subjects could speak freely, with no time limit. These exercises were partially identical to those found in GABI Child Language and Speech Database (Bóna et al., 2014) and Andrea Tóth's (2017) research.

Recordings were annotated on the segmental level using Praat 6.0.43 (Boersma \& Weenink, 2018). Disfluencies were marked by hand in all speech samples. The disfluencies analyzed in the current paper are the following: silent pauses, filled pauses, repetitions, as well as substitutions, insertions, and deletions. These disfluency types underwent frequency analysis, and in the case of silent and filled pauses, a duration analysis was conducted using a script. In Interviews, the first 300 syllables were taken into account, while the first 100 syllables of each Picture Story were analyzed. For the purposes of comparability, in cases where the syllable count in the speech of mildly intellectually disabled subjects did not reach the desired limit of 300 and 100 syllables but was at least $70 \%$ of these, the results were proportionally scaled to match other samples. Table 1 shows the syllable count produced in the two speech types by ID subjects. Statistical analyses were not conducted due to the relatively small number of subjects.

Table 1. Number of syllables in the full samples in the mildly intellectually disabled group

\begin{tabular}{lcc}
\multicolumn{1}{c}{ Subject } & Interview & Picture Story \\
ID1 & 106 & 60 \\
ID2 & $>300$ & $>100$ \\
ID3 & $>300$ & $>100$ \\
ID4 & $>300$ & $>100$ \\
ID5 & $>300$ & 74 \\
ID6 & 233 & 98 \\
ID7 & $>300$ & 56 \\
ID8 & 130 & $>100$ \\
ID9 & $>300$ & $>100$ \\
ID10 & $>300$ & $>100$
\end{tabular}

\section{Results}

When analyzing the samples, the following subjects and recordings were not included in the calculation of results. Subject ID1 was excluded from the analysis due to the fact that her syllable count did not reach the predetermined limit in either the Interview or the Picture Story. Disfluencies in the Interview sample of subject ID8 and in the Picture Story sample of subject ID7 were also disregarded during the evaluation for similar reasons.

\section{Frequency analysis of disfluencies}

On average, ID subjects produced 9.3 filled pauses, 32.6 silent pauses, and 2.5 repetitions during the first 300 syllables of the Interview samples. Subjects ID6 and ID7 did not produce any repetitions. Subject ID4 had the fewest filled pauses (3), while subject ID9 had the most (21). There were even more substantial differences between individual subjects when it came to silent pauses. Only 13 instances were detected in the first 300 syllables of subject ID7, whereas ID4 had 65 silent pauses in total. When it came to repairs, there was an average of 0.25 substitutions, 0.5 insertions, and 0.13 deletions among ID subjects. There were only two substitutions in total, both from subject ID9. Insertions were found in the speech of subjects ID3, ID4, and ID9. Only one deletion was detected, which belonged to subject ID3.

Among mentally healthy subjects, these numbers were the following in the Interview samples. On average, filled pauses occurred 8.6 times, silent pauses 20.8 times, and repetitions 3.4 times. In the first 300 syllables, there was an average of 1.3 substitutions, 0.3 insertions, and 0.5 deletions. This means that there were more silent pauses and insertions in the mildly intellectually disabled group, while the other disfluencies were more prominent among control subjects. This can be explained by the fact that the speech production (and perception) of intellectually disabled people is influenced by the weakness of stimulus processing functions (cf. Lukács \& Kas, 2014), and these people need more time to form their thoughts into words. Both silent and filled pauses, as well as insertion, are suitable for gaining some of the extra time needed.

In Picture Story samples, there was an average of 3.1 filled pauses, 18.0 silent pauses, and only 0.5 repetitions among ID subjects. Both substitutions and insertions occurred 0.25 times on average (with only two subjects producing them each), while the occurrence of deletions was 0.6 on average. It is important to note that while the frequency of occurring silent pauses was nearly identical in both sample types (close to 3.1 per 100 syllables), the frequency of filled pauses was much higher in Picture Story samples (18 per 100 syllables) than in Interview samples (10.9 per 100 syllables).

Picture Story samples of control subjects yielded the following results: in the 100 syllables analyzed, there was an average of 3.3 filled pauses, 10.4 silent pauses, and 0.1 repetitions and substitutions alike (one occurrence each, from $\mathrm{C} 4$ and $\mathrm{C} 10$ ). In this speech sample type, neither insertions nor deletions were found. 
If we compare the frequency of hesitations and repairs in total, it can be said that the former phenomena occurred more frequently in both speech sample types. Hesitations were more frequent among ID subjects, whereas more instances of repairs were collected from control subjects in the Interview (Figure 1).

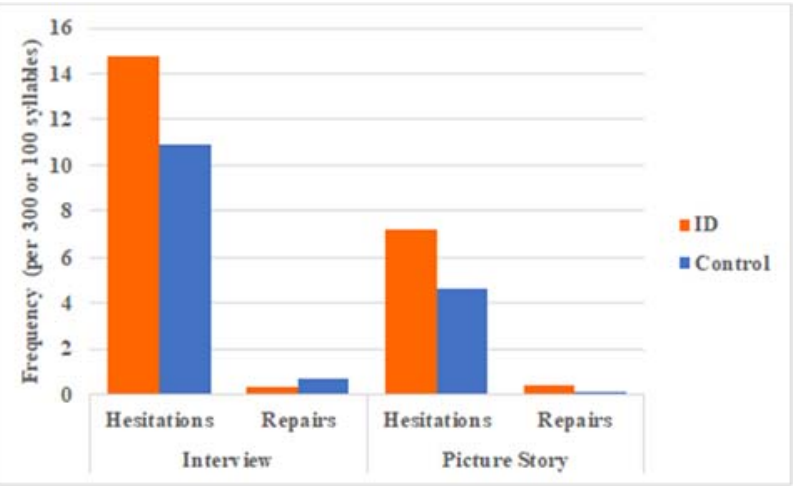

Figure 1. Average frequency of hesitations and repairs in the two speech types.

Hesitation and repair occurrences were analyzed collectively in both sample types. For the purposes of comparability, the total sum of disfluencies occurring in the speech of ID subjects was scaled up to make up for the two excluded samples in each speech type and match the sample size of control subjects. Table 2 shows the number of disfluencies detected in each complete set of samples after the scaling process.

Table 2. Total number of disfluencies produced by each group in both speech sample types.

\section{Interview}

\begin{tabular}{ccc}
$\begin{array}{c}\text { Subjects } \\
\text { ID }\end{array}$ & $\begin{array}{c}\text { No. of syllables total } \\
2400 \text { (scaled to 3000) }\end{array}$ & $\begin{array}{c}\text { No. of disfluencies } \\
452.4\end{array}$ \\
\hline Control & 3000 & 343 \\
\hline
\end{tabular}

\section{Picture Story}

\begin{tabular}{ccc}
$\begin{array}{c}\text { Subjects } \\
\text { ID }\end{array}$ & $\begin{array}{c}\text { No. of syllables total } \\
800 \text { (scaled to 1000) }\end{array}$ & $\begin{array}{c}\text { No. of disfluencies } \\
226.3\end{array}$ \\
\hline Control & 1000 & 139
\end{tabular}

As it can be seen, ID subjects produced a higher number of disfluencies in both speech sample types, therefore their speech can be described as less fluent. However, the same calculations were done without the inclusion of silent pauses, in which case, the results are quite different between the two sample types. Figure 2 shows that the rate of disfluencies is reversed, as overall, ID subjects produced 126.5 disfluencies (excluding silent pauses) and control subjects produced 141. At the same time, 46.8 disfluencies were detected in all Picture Story ID samples, while only 35 disfluencies occurred in samples from control subjects. This corroborates that (at least among the subjects of the current research) silent pauses have a significant role in spontaneous speech. The high frequency of silent pauses among ID subjects might be explained by the fact that there is no need to pay attention to articulatory expressions during this type of hesitation, therefore it can be used to gain more time for speech planning.

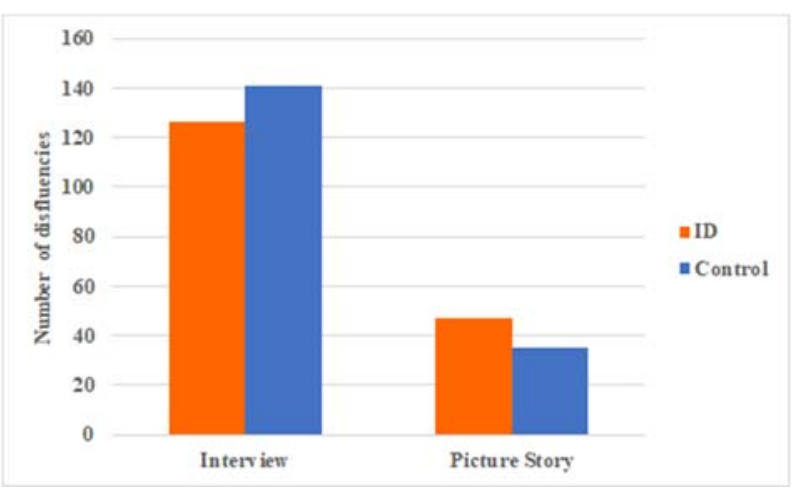

Figure 2. Number of disfluencies (without silent pauses).

\section{Duration of filled and silent pauses}

In the Interview, the filled pauses of ID subjects were 0.44 seconds long on average, while silent pauses lasted for 0.77 seconds. There was a large difference in the lowest and highest values between the two pause types. The shortest filled pause was 0.04 seconds long and the longest was 1.3 seconds, whereas the shortest silent pause was 0.06 seconds and the longest 5.8 seconds. As for control subjects, the average of filled pause lengths was 0.36 seconds, and silent pauses were 0.48 seconds long. These mean values, therefore, were higher among ID subjects.

There were no filled pauses in the Picture Story samples of subjects ID3, ID5, and ID10. Other ID subjects' filled pauses were 0.44 seconds long on average. The mean length of silent pauses was 0.87 seconds. Like in the Interview, the durations in the control subject group were shorter in Picture Story samples as well. Filled pauses were 0.38 seconds long, while silent pauses spanned an average 0.51 seconds.

If the pauses occurring in both speech types are taken into account, the average length of filled pauses from ID subjects was 0.44 seconds, while that of silent pauses was 0.80 seconds. The mean values for control subjects were 0.37 seconds (filled pauses) and 0.49 seconds (silent pauses). Figure 3 shows the length distribution of all recorded filled and silent pauses. It can be seen that silent pauses were lengthier in both subject groups, but as established before, the difference between filled and silent pauses was more prominent among ID subjects. 


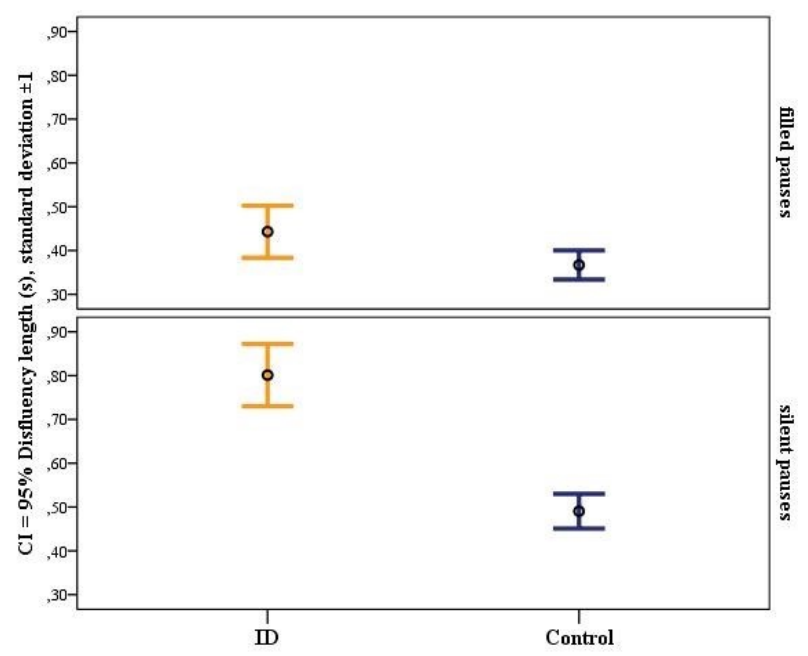

Figure 3. Length of filled and silent pauses in the two subject groups.

\section{Discussion and conclusion}

The first hypothesis was corroborated by our results, which can be traced back to numerous reasons. Hesitations include silent and filled pauses, which appeared more prominently among ID subjects. Hesitations allow the speaker to rethink their message and continue expressing their thoughts without inserting any new verbal elements.

Our findings also support the second hypothesis, as there were more disfluencies detected overall in both sample types of ID subjects when all six disfluency types were included, although there were meaningful individual differences. It is also important to note that when silent pauses were excluded from the analysis, it was shown that control subjects exhibited more disfluencies in the Interview. This discovery sheds light on the role silent pauses play in the spontaneous speech of intellectually disabled people. Repairs occurred sparingly in both sample types of ID subjects, which can be explained by the complexity of having to continue with the articulatory planning while simultaneously introducing new linguistic elements into the speech.

The third hypothesis, which presumed that the average duration of silent and filled pauses would be longer in the speech of ID subjects, was also corroborated. The reason behind this finding might be these subjects' difficulty in linguistic and speech performance. It is necessary to add that definite conclusions cannot be drawn from our results due to the relatively small number of subjects. During our analysis, considerable individual differences were shown in both subject groups.

Further steps of the research include increasing the sample size and introducing male subjects, which would provide an opportunity to uncover potential gender differences. Another addition is the analysis of prolongations, which will also be undertaken in the future. The authors hope that the results of this research can broaden the understanding of the speech production of mildly intellectually disabled adults and aid the development of therapy methods.

\section{Acknowledgements}

We thank the Department of Phonetics, as well as the MTA-ELTE "Lendület" Lingual Articulation Research Group at ELTE for the location and tools supplied for the current research.

\section{References}

Boersma, P. \& D. Weenink. 2018. Praat: Doing phonetics by computer (version 6.0.43). http://www.praat.org/ (accessed 1 January 2019).

Bóna, J. 2018. Disfluencies and disfluency clusters in cluttered, stuttered and typical speech. Beszédkutatás 26: 221-235.

Bóna, J., A. Imre, A. Markó, V. Váradi \& M. Gósy. 2014. GABI - Gyermeknyelvi beszédAdatBázis és Információtár [GABI - Children's Speech and Informational Database]. Beszédkutatás 22: 246-251.

Coppens-Hofman, M. C., H. R. Terband, B. A. Maassen, H. M. Van Schrojenstein Lantman-De Valk, Y. Van-Zaalen-op't Hof \& A. F. M. Snik. 2013. Disfluencies in the speech of adults with intellectual disabilities and reported speech difficulties. Journal of Communication Disorders 46(5-6): 484-494. https://doi.org/10.1016/j.jcomdis.2013.08.001

ICD-11 = International Classification of Diseases. 11th Revision. The global standard for diagnostic health information. 2018. https://icd.who.int/en/ (accessed 29 May 2019).

Lickley, R. J. 2015. Fluency and disfluency. In: M. A. Redford (ed.): The Handbook of Speech Production. Hoboken, NJ: Wiley Blackwell, 445-474. https://doi.org/10.1002 /9781118584156.ch20

Lukács Á. \& B. Kas. 2014. Nyelvelsajátítás és értelmi fogyatékosság [Language acquisition and mental disability]. In: Pléh Cs. \& Á. Lukács (eds.): Pszicholingvisztika 1-2.: Magyar pszicholingvisztikai kézikönyv [Psycholinguistics 1-2. Hungarian handbook on psycholinguistics] Budapest: Akadémiai Kiadó, 1383-1404.

Roberts, P. M., A. Meltzer \& J. Wilding. 2009. Disfluencies in non-stuttering adults across sample lengths and topics. Journal of Communication Disorders 42(6): 414-427. https://doi.org/10.1016/j.jcomdis.2009.06.001

Rossi, N. F., A. Sampaio, Ó. F. Gonçalves \& C. M. Giacheti. 2011. Analysis of speech fluency in Williams syndrome. Research in Developmental Disabilities 32(6): 2957-2962. https://doi.org/10.1016/j.ridd.2011.05.006

Tóth, A. 2017. A spontán beszéd a nem és az életkor függvényében gyermek- és fiatal felnöttkorban [Spontaneous speech in relation to gender and age in childhood and adolescence]. Ph.D. dissertation. Eötvös Loránd University, Budapest, Hungary. 